\title{
In-vitro fertilization of rabbit ova ovulated in vitro during ovarian perfusion
}

\author{
Y. Kobayashi, Rosemary Santulli, Karen H. Wright and E. E. Wallach
}

Department of Obstetrics and Gynecology, Pennsylvania Hospital and the University of Pennsylvania School of Medicine, Philadelphia, Pennsylvania 19107, U.S.A.

\begin{abstract}
Summary. During in-vitro perfusion of rabbit ovaries, ova that ovulated in response to hCG were recovered and cultured with spermatozoa capacitated in vivo. After culture for $30 \mathrm{~h}, 113(48.8 \%)$ of the ova underwent cleavage and were not degenerate. Of these 113 zygotes, 75 were successfully transferred to the oviducts of 14 gonadotrophintreated host rabbits. On Day 14 after transfer there were 14 implantation sites and 9 pregnancies proceeded to term. These data indicate that in-vitro ovulated ova can be fertilized in vitro and be used to establish normal pregnancies in a host rabbit.
\end{abstract}

\section{Introduction}

The technique of in-vitro ovarian perfusion has been useful for investigating the mammalian ovulatory process. The local effects of various agents on follicle growth, ovulation and ovum maturation can be examined by using in-vitro ovarian perfusion (Lambertsen, Greenbaum, Wright \& Wallach, 1976; Hamada, Bronson, Wright \& Wallach, 1977; Hamada, Wright \& Wallach, 1978, 1979; Wallach, Wright \& Hamada, 1978; Hamada et al., 1980; Kobayashi, Santulli, Wright \& Wallach, 1980, 1981a; Kobayashi, Wright, Santulli \& Wallach, 1983). Ova released in vitro have been recovered, cultured, transferred to a mated host, and observed to implant and produce viable offspring after fertilization in vivo (Kobayashi et al., 1981b). In-vitro fertilization techniques have been established for several species, with varied success rates (Brackett, 1979). The present study was designed to evaluate in-vitro fertilizability of rabbit ova ovulated in vitro during ovarian perfusion.

\section{Materials and Methods}

Ovaries of sexually mature virgin female New Zealand White (NZW) rabbits were removed and perfused to obtain ova ovulated in vitro. NZW males of proven fertility served as inseminators. Dutch Belted (DB) and NZW females served as hosts for the in-vitro fertilized ova. All female rabbits were isolated for 3 weeks before study, and kept under controlled light and temperature with free access to Purina Rabbit Chow and water.

The perfusion technique and surgical procedure, including arterial cannulation and ovarian removal, have been previously described in detail (Lambertsen et al., 1976; Hamada et al., 1978; Kobayashi et al., 1981c). Both ovaries of isolated NZW rabbits were removed at laparotomy and placed in separate perfusion chambers. An ovulation-inducing dose of hCG (100 i.u.) was added to the perfusing medium of each ovary at the onset of perfusion (Kobayashi et al., 1981c). Ovaries were perfused for $12 \mathrm{~h}$ at $37^{\circ} \mathrm{C}$ and $100 \%$ humidity. Throughout perfusion, ovaries were observed frequently for evidence of follicular growth and ovulation. 
When ovulation occurred, the extruded ovum in its cumulus mass was recovered from the surface of the ovary and washed 3 times in Brackett's defined medium (Brackett \& Williams, 1968). Ova were cultured under a thin layer of paraffin oil at $37^{\circ} \mathrm{C}$ and $100 \%$ humidity in an atmosphere of $5 \% \mathrm{CO}_{2}$ in air and minimal light (Brackett \& Williams, 1968).

Capacitated spermatozoa were obtained by mating a NZW female with 3 NZW males of proven fertility. Insemination was confirmed by the presence of spermatozoa in the vagina. The mating was scheduled $2 \mathrm{~h}$ before the onset of perfusion of the ovary which served as the source of eggs. This sequence enabled co-ordination of sperm recovery at $14 \mathrm{~h}$ after mating with the optimum ovum culture period ( $12 \mathrm{~h}$ after hCG). A laparotomy was performed on the mated female $14 \mathrm{~h}$ after mating to recover the spermatozoa. The cervico-vaginal junctions and utero-tubal junctions were clamped and each uterine horn was flushed with $4.0 \mathrm{ml}$ Brackett's medium using a 5-ml syringe and 19-gauge needle. The rabbit was killed immediately before the uterine flushing to minimize blood contamination of the recovered sperm/medium mixture. The recovered medium was examined microscopically. A concentration of spermatozoa $>10^{5} / \mathrm{ml}$ medium and sperm motility of $60-90 \%$ were considered satisfactory for in-vitro fertilization (Dandekar \& Fraser, 1976).

At $12 \mathrm{~h}$ after initial exposure of the ovary to hCG, cultured eggs that had ovulated in vitro were transferred to Petri dishes containing the sperm suspension. The $12 \mathrm{~h}$ gonadotrophin-toinsemination interval was used because previous experiments had indicated that $70.5 \%$ of eggs ovulated by $12 \mathrm{~h}$ after hCG in the perfusion medium are sufficiently mature (metaphase II, first polar body extruded) to undergo fertilization (Kobayashi et al., 1981 b). The eggs and spermatozoa were cultured in Brackett's medium under oil. At $4.5 \mathrm{~h}$ after exposure to capacitated spermatozoa, the eggs were removed from the sperm suspension and placed in fresh medium in which culture was continued.

In the first phase of this study, groups of eggs were examined after $8,26,30$ and $38 \mathrm{~h}$ of culture. Before examination, eggs were mechanically agitated 2 or 3 times to remove cumulus cells. If this method did not sufficiently release the granulosa cells, the eggs were subsequently treated with hyaluronidase (Fraser, Dandekar \& Vaidya, 1971). At 30 and $38 \mathrm{~h}$ of culture, all eggs required hyaluronidase treatment for removal of cumulus cells. The denuded eggs were examined microscopically. Fertilization was confirmed by the observation of 2 polar bodies, male and female pronuclei, or cleavage. Fertilized eggs were also assessed for signs of degeneration, including vacuolation, cytolysis, necrosis, changes in the shape of pronuclei and fragmentation.

In the second phase of the study, in-vitro ovulated and in-vitro fertilized eggs were transferred to host rabbits which had been treated i.v. with 100 i.u. hCG at the time when ovarian perfusion had started. The in-vitro ovulated and fertilized eggs were cultured for $30 \mathrm{~h}$. The eggs were then removed from the culture dish by pipette and the medium was changed twice to eliminate the oil layer. Eggs for transfer were not treated with hyaluronidase. The cultured eggs that had been exposed to spermatozoa were examined microscopically. Undegenerated eggs that had undergone cleavage were transferred to host rabbits at laparotomy. The fertilized eggs (2-4-cell stage) in $20 \mu l$ culture medium were placed in the ampulla of each oviduct using a glass pipette (range 3-11 eggs/host). Each host rabbit was subjected to a second laparotomy 14 days after egg transfer to determine the number, size, and location of implantation sites in each uterine horn. Bicillin (300 000 i.u. : Wyeth Laboratories, Philadelphia, Pennsylvania) was administered intramuscularly, after surgery. At 32 days after transfer, cages were examined frequently for the presence of offspring.

\section{Results}

Study 1. Thirty-one ovaries were perfused and 151 in-vitro ovulated ova were recovered and cultured. As shown in Table 1, the highest percentage of fertilization was evident at $26 \mathrm{~h}$ and pronuclear and cleaved stages were obtained. Culture for $30 \mathrm{~h}$ yielded the greatest percentage of undegenerated cleaved ova and this time was therefore used for Study 2. 
Table 1. In-vitro fertilizability of rabbit ova ovulated during ovarian perfusion

\begin{tabular}{ccccc}
\hline & \multicolumn{4}{c}{ No. (\%) of ova } \\
\cline { 2 - 5 } $\begin{array}{c}\text { Culture time } \\
\text { (h) }\end{array}$ & Cultured & With pronuclei & Cleaved & Total fertilized \\
\hline 8 & & & & \\
26 & 48 & $26(54 \cdot 2)$ & - & $26(54 \cdot 2)$ \\
30 & 16 & $5(31 \cdot 3)$ & $5(31 \cdot 3)$ & $10(62 \cdot 5)$ \\
38 & 41 & - & $20(48 \cdot 8)$ & $20(48 \cdot 8)$ \\
& 46 & - & $18(39 \cdot 1)$ & $18(39 \cdot 1)$ \\
\hline
\end{tabular}

Study 2. In-vitro perfusion of 52 rabbit ovaries yielded 234 ovulated ova. After culture for $30 \mathrm{~h}$, 113 of the 234 ova $(48.3 \%)$ had cleaved and showed no evidence of degeneration. Of the 113 zygotes, 75 were successfully transferred to $N Z W(N=4)$ and $D B(N=10)$ hosts. The reduction in number of eggs at this stage of the procedure was related to technical problems encountered in the transfer process ( 22 eggs) or to complications associated with the host (16 eggs), including anaesthetic death or infection. Of the 75 zygotes transferred, $14(18.7 \%)$ implanted in 7 hosts as observed at laparotomy on Day 14. The greatest percentage loss of eggs was experienced at the implantation step. Nine of the 14 pregnancies ( $12 \%$ of the transferred zygotes, $3.8 \%$ of the original ova) proceeded to term. This figure compares with $18 \%$ term delivery of in-vitro fertilized, in-vivo ovulated rabbit ova (Mills, Jeitles \& Brackett, 1973). All of the offspring resulting from the procedure were completely white.

\section{Discussion}

The demonstration that ova ovulated in vitro are also capable of fertilization in vitro confirms that the in-vitro perfused rabbit ovary is suitable for studying the ovulated ovum as well as the ovulation process under various experimental conditions.

The low pregnancy yield $(3.8 \%$ of 234 in-vitro fertilized ova) may be compared with that recently achieved in human in-vitro fertilization and embryo transfer. The attrition rate in this investigation, as in human experience thus far reported, appears to be greatest at the step of embryo transfer and implantation (Biggers, 1981). The techniques described in this report can be applied to the study of ovum maturation and fertilizability following pertubation of the normal time sequence of ovum maturation and ovulation by use of pharmacological agents.

We thank L. Rubin and T. J. Henry for technical assistance and H. Kitai, M.D. and A. Bongiovanni, M.D. for critical review of the manuscript. Research for this project was supported by NIH Grant HD-05948, the Connelly Foundation and the Mitchell and Lillian Duberstein Foundation.

\section{References}

Biggers, J.D. (1981) In vitro fertilization and embryo transfer in human beings. N. Eng. J. Med. 304, 336342.

Brackett, B. (1979) In vitro fertilization and its assessment with embryo culture. In Animal Reproduction, pp. 171-193. Ed. H. W. Hawk. Allanheld, Osmun and Co., Inc., Montclair.

Brackett, B.G. \& Williams, W. (1968) Fertilization of rabbit ova in a defined medium. Fert. Steril. 19, 144155.

Dandekar, P. \& Fraser, L. (1976) A comparison of invitro fertilization of rabbit eggs using spermatozoa recovered from the uterus or vagina. J. Reprod. Fert. 46, $77-81$.

Fraser, L., Dandekar, P. \& Vaidya, R. (1971) In vitro fertilization of tubal rabbit ova partially or totally denuded of follicular cells. Biol. Reprod. 4, 229-233.

Hamada, Y., Bronson, R.A., Wright, K.H. \& Wallach, E.E. (1977) Ovulation in the perfused rabbit ovary: the influence of prostaglandins and prostaglandin inhibitors. Biol. Reprod. 17, 58-63.

Hamada, Y., Wright, K.H. \& Wallach, E.E. (1978) In vitro reversal of indomethacin blocked ovulation by prostaglandin $\mathrm{F}_{2 \alpha}$. Fert. Steril. 30, 702-706. 
Hamada, Y., Wright, K.H. \& Wallach, E.E. (1979) The effects of progesterone and human chorionic gonadotropin on ovulation in the in vitro perfused rabbit ovary. Fert. Steril. 32, 335-339.

Hamada, Y., Schlafi, S., Kobayashi, Y., Santulli, R., Wright, K.H. \& Wallach, E.E. (1980) Inhibitory effect of prolactin on ovulation in the in vitro perfused rabbit ovary. Nature, Lond. 285, 161-163.

Kobayashi, Y., Santulli, R., Wright, K.H. \& Wallach, E.E. (1980) Induction of ovulation in vitro by prostaglandin $\mathrm{F}_{2 a}$. Biol. Reprod. 22, Suppl. 1, 186, Abstr. 113.

Kobayashi, Y., Santulli, R., Wright, K.H. \& Wallach, E.E. (1981a) The effect of prostaglandin synthesis inhibition by indomethacin on ovulation and ovum maturation in the in vitro perfused rabbit ovary. Am. J. Obstet. Gynec. 141, 53-57.

Kobayashi, Y., Santulli, R., Wright, K.H. \& Wallach, E.E. (1981 b) Fertilizability of ova ovulated and recovered from rabbit ovaries perfused in vitro. Science, N.Y. 213, $1127-1128$.
Kobayashi, Y., Wright, K.H., Santulli, R. \& Wallach, E.E. (1981c) Ovulation and ovum maturation in the rabbit ovary perfused in vitro. Biol. Reprod. 24, 483-490.

Kobayashi, Y., Wright, K.H., Santulli, R. \& Wallach, E.E. (1983) The effect of histamine and histamine blockers on the ovulatory process in the in vitro perfused rabbit ovary. Biol. Reprod. 28, 385-392.

Lambertsen, C.J., Greenbaum, D.F., Wright, K.H. \& Wallach, E.E. (1976) In vitro studies of ovulation in the perfused rabbit ovary. Fert. Steril. 27, 178-187.

Mills, J.A., Jeitles, G.C. \& Brackett, B.G. (1973) Embryo transfer following in vitro and in vivo fertilization of rabbit ova. Fert. Steril. 24, 602-608.

Wallach, E.E., Wright, K.H. \& Hamada, Y. (1978) Investigation of mammalian ovulation with an in vitro perfused rabbit ovary preparation. Am. J. Obstet. Gymec. 132, 728-738.

Received 20 July 1982 